Universidade de São Paulo

Escola de Engenharia de São Carlos

Departamento de Engenharia Mecânica

\title{
Dinâmica veicular relativa ao ride de veículos e métricas para sua avaliação
}

\author{
Autor: Eng. Odilon Terreri Perseguim \\ Orientador: Prof. Dr. Álvaro Costa Neto
}

Tese apresentada à Escola de Engenharia de São Carlos da Universidade de São Paulo, como parte dos requisitos para a obtenção do título de doutor em Engenharia Mecânica

São Carlos

2005 


\section{Agradecimentos}

Ao prof. Dr. Álvaro Costa Neto pela orientação no desenvolvimento desse trabalho.

À Ford Motor Company por permitir a utilização de resultados de veículos reais para ilustrar a teoria apresentada nesse trabalho.

À João Antonio da Silva Filho, Fermando Mendonça, Antônio DeLucca pelo apoio durante o desenvolvimento desse trabalho.

Aos amigos José Paulo de Angelo Sanchez, Claudiomar Cardoso Cunha, Vanessa Barbosa de Magalhães e aos demais amigos da Ford pelas valiosas contribuições.

À minha família, minha mãe, meu pai e minha irmã pelo apoio em todos os momentos que precisei.

A Deus, acima de tudo e de todos. 